\title{
Transformation of Blockchain as Social Good
}

\author{
${ }^{1}$ Marat R. Safiullin, ${ }^{2}$ Mikhail V. Savelichev, ${ }^{3}$ Leonid A. EIshin \\ 1,3 Kazan Federal University \\ ${ }^{2,3}$ State Budgetary Institution Center of Perspective Economic Researches of Academy of Sciences of the Republic \\ of Tatarstan \\ Email:Leonid.Elshin@tatar.ru
}

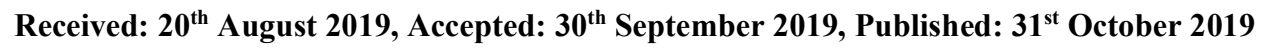

\begin{abstract}
Blockchain is currently considered as a key technology that can significantly reduce the level of transaction costs in the economy, reduce the level of economic and financial risks, and increase the efficiency of economy and financial sector.

In this regard, it is relevant to study the possible trajectories of blockchain transformation under conditions when the state has not yet developed a universal model for blockchain integration into the economic system.

The blockchain research method as a good is represented by economic sociodynamics, which studies the typology of goods and their transitions under the influence of interests that society presents to a particular product or service. The models of dynamics of social groups of M. Olsen and R. Putnam are also used.

The endowment of blockchain with the features of a social good by the state shall not be accompanied by the deprivation of blockchain of the properties of a private good that can satisfy private, not just public interests. This will create conditions for increasing the share of Putnam's groups and reducing the share of Olsen's groups, which will increase the level of trust in society and stimulate the improvement of macroeconomic indicators, such as economic growth and increase in the GDP investment share.
\end{abstract}

Keywords

Blockchain, Good, Economic Sociodynamics, Trust, Transaction Costs, Putnam's Groups, Olsen's Groups

\section{Introduction}

The potential for widespread use of blockchain technology in the financial and economic spheres is due to the possibility of a significant reduction in transaction costs by increasing the security of transactions, reducing the cost of involving third parties in transactions, and using smart contracts. $[1,2,3]$

The goal of our study is to consider blockchain as a good, the consumption of which creates groups that differ in their impact on society as a whole. $[4,5]$

In terms of view of economic sociodynamics, blockchain is a communal good that satisfies private interests, but at the same time is in the process of acquiring features of a social good, that is, the ability to satisfy the interests of society, not reducible to private interests.

The blockchain sociodynamics as a good can be considered within the framework of the models propsed by M. Olsen [6] and R. Putnam [7]. At the stage of blockchain emergence as a communal good, Olsen's groups formed around it, while endowing the blockchain with the features of social good created favorable conditions for the formation of Putnam's groups. Such dynamics of various types of groups allows explaining the reasons for the increase in trust in society, provided that the blockchain goes into the category of mixed communal good.

At the same time, the desire to limit the blockchain to exclusively social utility will resume the process of forming Olsen's groups around this technology, which can level the trend of increasing trust in society and lead to an increase in transaction costs.

\section{Methods \\ Olsen's Groups and Putnam's Groups}

In the classical works of M. Olsen and R. Putnam on the issues of social dynamics, two different models of the impact of social groups on the economy are presented. Olsen's model states that small groups united by a common interest have disproportionately large opportunities to pursue their own interests, often to the detriment of wider social groups. Putnam, on the basis of comparing the level of economic development of the north and south of Italy, formulates a different model in which the more developed various kinds of associations, unions, groups are, the more this stimulates the efficiency of the state and increases the economic effectiveness.

And Olsen bases his conclusions on the fact that the larger the group is, the more difficult it is to achieve unity of opinion within it and determine the ways of putting those opinions into practice. In addition, competition for leadership inevitably arises in large groups, such as trade unions, parties, taxpayers, consumers, fractions, which weakens or completely negates their ability to protect the interests of their individuals. And, on the contrary, compact, relatively small groups of like-minded people are devoid of such shortcomings, they are united not only by the unity of views, but also the size of possible gain will be incommensurably greater, if lobbying for their interests is successful. At the same time, the gain of a wider group will be distributed among such a number of participants that it will turn out to 
be small, and no group member will put much effort into it for the sake of receiving it. The excessive distribution of such groups in society leads to negative external effects, distortions in the economic policy of the state, since the decisions taken are focused on the interests of a limited circle of people. According to Olsen's studies, this reduces the volume of investments, distorts the sectoral distribution of investment resources, slows down the level of innovation activity, and slows down economic growth.

Putnam's model considers wide membership in various groups, associations, and associations as a source of strengthening trust and social ties both within such groups and in society as a whole. Associations develop the habit of interacting, forming a common opinion, trusting other people with each other in their members with each other in their members; moreover, not necessarily the members of the same association. Such groups have positive external effects that are assigned by the whole society. The spread of Putnam's groups increases the level of trust in society, increases the effectiveness of social interactions, which has a positive effect on economic dynamics. An example of society with the dominance of Putnam's groups is Silicon Valley, where there is a developed network of informal and formal relationships between developers of advanced technologies.

The approaches of Olsen and Putnam shall be considered as complementing each other, because both forms of group behavior are observed in real society.

Economic Sociodynamics

Economic sociodynamics recognizes the existence of social goods, which are not limited solely to the sum of private goods.

At the same time, social goods have two criteria properties: (a) if they are available to someone, then they are available to everyone, or the property of non-exclusion, (b) their consumption by one does not prevent the consumption of others (non-rivalry). At the same time, these criteria are rather vague and require formulation of clearer signs of a public good.

An important aspect is the presence of the primary consumption effect in social goods, which is assigned directly by the consumer of this good, and the secondary effect, which is consumed by society as a whole. An example of such an effect is the view of theatrical production, where the viewer receives directly private pleasure (the primary effect), but the secondary effect is the general cultural development of society, which, for example, increases human capital. The theory of socioeconomic dynamics shows that the conditions that determine the existence of communality properties in the goods, i.e. non-exclusion and non-rivalry in consumption, with the development of institutional structure of society, technological progress, are changing. As a result, there are opportunities to overcome communality, as a result of which these goods turn into private goods. Thus, the first law of economic sociodynamics is formulated as follows: as a development result of the institutional environment and technological progress, the cycles of communal goods asymptotically disappear, and the goods themselves begin to evolve within the boundaries of the cycle of private goods.

Blockchain is a communal good that evolves into a mixed communal good. The next stage of its evolution will be the transformation into a communal good and, at the final stage, a private good.

\section{Results and Discussion}

\section{Endowing Blockchain with the Social Utility Functions}

It is necessary to analyze the mechanism of endowing blockchain as a communal good with the social utility functions that transform it into a mixed communal good and generate the secondary consumption effect described above. There is a specific mechanism to reduce the individual utility of communal goods in market conditions. As a result, the marginal individual utility of the communal good decreases, but usually not due to a decrease in the value of each additional unit of goods, but as a result of the "communal apartment" effect [4, p. 245].

Initially, blockchain served as a platform for the issue and circulation of Bitcoin cryptocurrency, which, according to its creator S. Nakamoto [2], was devoid of the shortcomings of finite currencies: the possibility of excessive issue provided speed and anonymity of payments, and was protected from fakes and double spending due to cryptographic mechanism.

However, over some time, blockchain began to attract more attention, alternative cryptocurrencies arose. Bitcoins and other cryptocurrencies began to be used as a speculative tool, which led to a significant increase in their quotes on the exchange. There was a situation for the cryptocurrency users, who were engaged in its "mining", where speculative operations with cryptocurrency turned out to be no less profitable than its direct mining.

There was a decrease in the individual usefulness of this good, while its social usefulness has been increasing at the same time. De facto, the market began to gradually integrate the blockchain and use it for its needs, as a result of which the incentives for blockchain participants to support it on an individual basis were significantly reduced. Large groups of "cryptocurrency miners", who organized "computer factories" or "mining" pools for cryptocurrency mining, began to crowd them out, thereby further reducing the individual utility the blockchain, while increasing social utility. In turn, the cautious attitude of many states to this good, in which they saw a source of danger for the financial and economic systems and even for the security of the state as a whole, also negatively affected the individual usefulness of the good. [8]

At the same time, there is another mechanism for endowing good with features of social utility, which is associated with the level of trust that is observed in society. 
Formation of Olsen's Groups and Putnam's Groups in Relation to the Blockchain Sociodynamics

It is necessary to distinguish between trust as an individual good and trust as a social good. In the studies conducted by Knack, Keefer, Zak [9, 10, 11], trust was measured sociologically by directly interviewing the citizens, that is, based on the trust model as Lindahl's good [12], when the need for trust in society is the sum of individual demand curves on a public product, in particular such a specific product, which is trust. At the same time, only a fairly narrow circle of blockchain participants can benefit from the benefits of increasing blockchain-based trust in the first phase, since this technology has not yet been entered into the regulatory field of most countries and is in a kind of "gray" area.

Here we are faced with the phenomenon of forming Olsen's groups, which are distinguished by a high level of trust within the group, despite the fact that group members experience a lower level of trust in those who are not part of the group. The spread of blockchain technology will inevitably be accompanied by a regulatory regulation of its existence and application in the economic transactions, which will significantly expand the number of those who will use the blockchain on an ongoing basis. Given that there are significant prerequisites for the widespread occurrence of blockchain in the financial sector $[13,14,15]$, which is distinguished by the massive number of consumers of its goods and services, one shall expect the transformation of Olsen's groups into Putnam's groups, for which an increase in trust within a group or association leads to an increase in trust to those, who are not directly included in this group or association. This increases the level of trust in society as a whole.

Olsen's groups are formed not only among blockchain supporters and active users, but also among those, who consider this technology as a threat to their welfare. These may be large financiers, for whom the spread of cryptocurrencies poses a direct threat to their business, government officials convinced that blockchain and cryptocurrencies pose a threat to the national economy, as well as the financial and credit system At the same time, it can be noted that at a certain stage, the interests of Olsen's groups of blockchain users and its opponents converge to a certain extent. For blockchain users, this technology is seen as a tool to free themselves from the restrictions that the state and, in particular, the financial institutions impose on them. Therefore, the less the state will try to regulate the use of this technology, the better it is. Creation of special conditions in society for increasing the share of Olsen's groups beyond a certain limit, and such groups always exist, because they arise for various reasons, impedes the formation of Putnam's groups at the same time, thereby reducing the level of trust in the society that these groups generate and decreasing the level of human capital, since trust acts as one of its components.

From the point of view of economic sociodynamics, this means that when a blockchain moves from a communal good to a mixed one, its evolution takes place within the framework of a quasi cycle, during which local fluctuations in the social usefulness of the good take place. This is due to the fact that the recognition of blockchain as a legal platform for economic transactions is very controversial. A number of countries have legalized activities based on blockchain and cryptocurrencies. Others do not yet regulate this activity at the level of national legislation, as, for example, in the Russian Federation. Nevertheless, the wider the recognition of blockchain at the national and international levels is, the higher its social utility is and the more confidently its transformation into a mixed communal good takes place.

Sociodynamics predicts the possibility of switching the good from one graph describing its evolution to another graph, where the good may undergo a different transformation. Thus, blockchain can jump onto the evolution trajectory within the framework of the social good at the stage of a mixed communal good, where its evolution will stop, that is, blockchain transformation into a private good will not happen. Another possible option: blockchain goes into a group of social goods, losing its individual utility and maintaining its social utility. This can happen when the state prohibits the use of blockchain by private individuals, restricting the use of this technology only for public needs, such as storing archives, databases of pension funds, etc.

It can be predicted that the widespread use of this technology stimulates its transformation into completely different types, which can be called conditionally blockchain 3.0, similar to blockchain 1.0, which was created as the basis for the issue and use of Bitcoin cryptocurrency, and blockchain 2.0, where this technology significantly expanded the application scope through tokens and smart contracts. Further blockchain transformation for use on the Internet of things, storage of information will reduce, and then eliminate the need for the state to specifically regulate directly the blockchain technology itself in a special way. The development of this good will consist in overcoming non-exclusion and non-rivalry at a new technological turn, turning blockchain into a private good.

\section{Summary}

Blockchain as a goods has an impact on the group dynamics that occurs in the process of endowing it with social utility on the part of the state. At the first stage of blockchain existence as a communal good, groups were formed regarding its consumption that can be attributed to Olsen's groups. They are characterized by a high level of trust between members of such groups and a low level of trust in those who are not the group members. The proliferation of Olsen's groups is accompanied by a decrease in the level of trust in society, which negatively affects economic efficiency. The gradual endowment of blockchain with the features of a social good strengthens another type of groups, Putnam's groups. For them, a high level of trust between group members stimulates an increase in the level of trust in those who are not the group members. Thus, the general level of trust in society arises and thereby stimulates a higher 
level of economic efficiency. The practice of depriving the blockchain of the private good attribute and endowing it with exclusively social utility can create favorable conditions for a new cycle of strengthening Olsen's groups and weakening Putnam's groups.

\section{Conclusions}

The mechanism of the relationship between blockchain evolution as a good and group dynamics in society presented in the article indicates the need on the part of the state to preserve the attributes of both social and private good for the blockchain, without limiting the scope of its application exclusively to public sectors. Thus, its private and social usefulness will be maximized as a benefit conducive to increasing confidence and reducing transaction costs.

\section{Acknowledgements}

The study is carried out due to the grant of the Russian Science Foundation (project No. 19-18-00202)

This article is performed at the expense of the subsidy allocated to Kazan State University for the fulfillment of the state task in the field of scientific activity (No. 26.9776.2017/BCH (Russian: 26.9776.2017/БЧ)

\section{References}

1. Wang A.W. Crypto Economy. How Blockchain, Cryptocurrency, and Token-Economy Are Disrupting the Financial World. Skyhorse Publishing, 2018, 148 p.

2. Nakamoto S. Bitcoin: A peer- to- peer electronic cash system. Bitcoin.org. 2008. URL: https://bitcoin.org/bitcoin.pdf

3. Vigna P. and Casey M.J. The Truth Machine. St. Martin's Press, 2018, 320 p.

4. Rubinstein A.Ya. Economics of public preferences. SPb.: Aletheia, 2008. - 560 p.

5. Greenberg R., Rubinstein A. Economic sociodynamics. M., 2000.

6. Olson, M. The rise and decline of nations. New Haven: Yale University Press, 1982, 276 p.

7. Putnam R.D. Making democracy work: Civic traditions in modern Italy. Princeton: Princeton University Press, 1993, 258 p.

8. Herian R. Regulating blockchain: critical perspectives in law and technology. Abingdon, Oxon; New York, NY: Routledge, 2019, 178 p.

9. Knack S., Keefer P. Does social capital have an economic payoff? A cross-country investigation. Quarterly Journal of Economics 112, 1997, p. 1251-1288.

10. Knack S. Groups, growth and trust: Cross-country evidence on the Olson and Putnam hypotheses. Public Choice 117, 2003, p. 341-355.

11. Zak P., Knack S. Trust and growth. The Economic Journal, 111 (April), 2001, p.295-321.

12. Lindahl E. Positive Losung, Die Gerechtigkeit der Besteuerug // Classics in the Theory of Public Finance. 4th Impression / R.S.Musgrave, A.T.Peacock (eds.). London, 1967.

13. Tilooby A. "The Impact of Blockchain Technology on Financial Transactions." Dissertation, Georgia State University, 2018. https://scholarworks.gsu.edu/bus_admin_diss/103

14. Business Transformation through Blockchain, Vol.I. Editors: Treiblmaier H., Beck R. (Eds.), 2019, 290 p.

15. Business Transformation through Blockchain, Vol.II. Editors: Treiblmaier H., Beck R. (Eds.), 2019,362 p. 